\title{
Shape-dependent electrocatalytic activity of free gold nanoparticles toward glucose oxidation
}

\author{
Seydou Hebié • K. Boniface Kokoh • Karine Servat • \\ Teko W. Napporn
}

Published online: 26 November 2013

(C) The Author(s) 2013. This article is published with open access at SpringerLink.com

\begin{abstract}
The synthesis of shape and size-controlled free gold nanoparticles (AuNPs) was achieved by wet chemical methods. The UV-vis spectroscopy measurements and transmission electron microscopy characterizations confirmed the fine distribution in size and shape of the AuNPs. The zeta potential measurements permitted the evaluation of the stability of the AuNPs suspension. For the first time, the shape dependence on the electrocatalytic activity of these NPs is thoroughly investigated. The underpotential deposition (UPD) of lead reveals that their crystallographic facets are affected by their shape and growth process. Moreover, the glucose oxidation reaction strongly depends on the shape of AuNPs. Indeed, the gold nanocuboids (GNCs) and the spherical gold nanoparticles (GNSs) are significantly more active than the gold nanorods (GNRs) followed by the polyhedrons (GNPs). The oxidation process occurs at low potential for GNCs whereas the current densities are slightly higher for GNSs electrodes. Most importantly, the control of the shape and structure of nanomaterials is of high technological interest because of the strong correlation between these parameters and their optical, electrical and electrocatalytic properties.
\end{abstract}

Keywords Gold nanoparticles · Size · Shape · Lead · UPD · Electrocatalysis · Glucose oxidation

Electronic supplementary material The online version of this article (doi:10.1007/s13404-013-0119-4) contains supplementary material, which is available to authorized users.

S. Hebié · K. B. Kokoh · K. Servat • T. W. Napporn $(\bowtie)$

IC2MP, UMR 7285 CNRS, Université de Poitiers, 4, rue Michel

Brunet B-27, BP 633, 86022 Poitiers Cedex, France

e-mail: teko.napporn@univ-poitiers.fr

\section{Introduction}

Gold nanoparticles continue to emerge in many scientific fields because of their unique physicochemical properties such as optical, magnetic, electronic and catalytic properties compared to those of the bulk material. These unusual properties make them able to offer a wide range of applications [1-3]. Since these properties strongly depend on the shape, the size, the crystallinity and the surface structure of nanoparticles, significant progresses in synthesis methods emerged in recent years for controlling the particles' morphology [4-10]. Among the mentioned synthesis approaches in the literature, the template method, the electrochemical method, the microwave rapid heating, the laser ablation, and the seed-mediated growth methods have been undertaken to yield gold nanoparticles with uniform sizes and morphologies [5, 9, 11-14]. The size and shape control in a wet chemical process has the advantages of low cost and easy scale-up over methods. Within the seedmediated growth methods, hexadecyltrimethylammonium bromide (CTAB) has been commonly used as a capping agent. It is known as a structure-directing molecule that interacts differently with gold facets in the order $(100) \approx(110)>(111)$ [15]. The preferential adsorption of $\mathrm{CTAB}$ on the gold surface allows the preparation of nanoparticles with specific shape and surface crystallographic orientation. It is found that some metallic cations added to the growth solution, such as $\mathrm{Cu}^{2+}$ or $\mathrm{Ag}^{+}$, are effective agents that favor the control of the NPs' shape [14, 16]. In fact, $\mathrm{Cu}^{2+}$ ions are adsorbed on (111) facets, selectively retarding their growth rate and preferentially leading to a particle growth along (100) facets [16]. The role of $\mathrm{Ag}^{+}$is similar but promotes the rod-shaped growth [14]. The possibility of controlling the crystallography on the surface of AuNPs has been investigated on gold nanomaterials since the electrocatalytic reactions are structure sensitive $[17,18]$. On the one hand, the electrochemical reactivity of a molecule depends on the facility of the surface electrons of the particles to promote a 
catalytic process. Therefore, the (111), (100) and (110) reflection planes of a face-centered cubic (fcc) metal such as noble metals have different surface atom densities, electronic structures and chemical reactivity. Thereby, an effective control of the nanocrystal preparation with different shapes becomes essential. On the other hand, a modeling approach by Nørskov et al. [19] showed that small gold nanoparticles can exhibit unexpected catalytic activity toward the carbon monoxide oxidation.

Moreover, gold nanoparticles with high electrocatalytic activities play crucial roles in the performance of biofuel cell design and electrochemical sensors [20]. In the literature, the electrocatalytic oxidation of glucose in alkaline medium was studied on $\mathrm{Cu}, \mathrm{Ag}-\mathrm{Au}, \mathrm{Au}-\mathrm{Pt}, \mathrm{Ag}, \mathrm{Pt}$ and $\mathrm{Au}$ materials [21-31]. In alkaline and neutral media, gold appeared as an excellent electrocatalyst for several saturated oxygenated organic compounds due to its catalytic activity at low potentials compared to the other catalysts in the same conditions [22, 25, 30]. In addition, Vuyyuru et al. [32] showed that Au has a better catalytic activity than $\mathrm{Pt}, \mathrm{Pd}, \mathrm{Ru}$ and $\mathrm{Rh}$ for biomassderived 5-hydroxymethylfurfural at $\mathrm{pH} 13$.

The electrooxidation of glucose has been investigated on gold single crystal electrodes $[33,34]$ and also on the anisotropic gold octahedral, nanobelts, and nanoplates whose edges exhibited either (110) or (111) facets [26, 31]. For the oxidation of glucose on gold material in alkaline medium, it was shown that the (110) surface is more active than that of (111) $[26,31,34]$. Therefore, the size and the surface structure of the gold nanoparticles are important parameters for investigating glucose oxidation. The surface sensitive reactions, such as underpotential deposition (UPD) of adatoms, i.e. lead on gold, are a useful tool for characterizing its surface structure distribution [17, 18]. More recently, Hebié et al. [28] showed that the contribution of (100) facets on gold nanorods enhances the electroactivity toward the glucose oxidation.

The present investigation aims to establish a relationship between the shape, the surface structure, and the electrocatalytic activity of gold nanoparticles. Therefore, different shapecontrolled gold nanoparticles were synthesized. The UPD of lead is considered as the main electrochemical characterization technique. Even if the shape of the AuNPs is considered as an important parameter, the surface reactivity of such particles is discussed in terms of structure involved in the chemical reaction process.

\section{Experimental section}

Reagents, apparatus and measurements Hydrogen tetrachloroaurate (III) trihydrate $\left(\mathrm{HAuCl}_{4} \cdot 3 \mathrm{H}_{2} \mathrm{O}, 99.9 \%\right.$ ), sodium borohydride $\left(\mathrm{NaBH}_{4}, 99 \%\right)$ and D-glucose $(>99 \%)$ were obtained from Sigma-Aldrich. In addition, ascorbic acid (AA, >99\%) was received from Alfa Aesar, silver nitrate $\left(\mathrm{AgNO}_{3},>99 \%\right)$ was purchased from Fisher Scientific and CTAB (>99 \%) was obtained from Fluka. All reactants were used without further purification.

For the electrochemical experiments, the glassware was cleaned according to the methodology described elsewhere $[28,35]$. Afterwards, the glassware was rinsed with hot water and kept in aqua regia solution for an hour and finally rinsed with ultrapure water $\left(18.2 \mathrm{M} \Omega \mathrm{cm}\right.$ at $\left.20^{\circ} \mathrm{C}\right)$.

\section{Nanoparticles preparation}

AuNPs of different shapes (spherical, rod, polyhedron and cuboids) were synthesized by wet chemical methods in the presence of CTAB used as capping agent. Such morphology control enables the production of nanoparticles with specific shapes and surface types. It could therefore allow electrocatalytic reactions with great selectivity. The details of the synthesis process were reported elsewhere $[5,14,16,28]$.

Spherical gold nanoparticle preparation In a clean $10 \mathrm{~mL}$ vial tube, $0.125 \mathrm{~mL}$ of $10 \mathrm{mmol} \mathrm{L}^{-1} \mathrm{HAuCl}_{4}$ was mixed with $3.75 \mathrm{~mL}$ of an aqueous solution of $0.1 \mathrm{~mol} \mathrm{~L}^{-1} \mathrm{CTAB}$. Then, $0.30 \mathrm{~mL}$ of an ice-cold $0.05 \mathrm{~mol} \mathrm{~L}^{-1} \mathrm{NaBH}_{4}$ solution was added to the previous solution all at once under stirring for $2 \mathrm{~min}$. Rapidly, the mixture turned light brown indicating the formation of gold seeds. Finally, the solution was kept undisturbed at a constant temperature of $27^{\circ} \mathrm{C}$ for $2 \mathrm{~h}$ before its use for growing anisotropic nanoparticles. After aging the same solution for 1 day, it was used as spherical gold solution (GNSs).

Gold nanorod preparation This procedure requires the preparation of the growth solution as follows. In a clean vial tube, appropriate quantities of reactants were placed, namely $4.75 \mathrm{~mL}$ of $0.1 \mathrm{~mol} \mathrm{~L}^{-1} \mathrm{CTAB}, 0.2 \mathrm{~mL}$ of $0.1 \mathrm{~mol} \mathrm{~L}^{-1}$ $\mathrm{HAuCl}_{4}$ and $30 \mu \mathrm{L}$ of $0.01 \mathrm{~mol} \mathrm{~L}^{-1} \mathrm{AgNO}_{3}$ in this order and mixed gently. The solution appeared bright brown-yellow. Then, $37 \mu \mathrm{L}$ of freshly prepared $0.1 \mathrm{~mol} \mathrm{~L}^{-1} \mathrm{AA}$ was added to the solution which became rapidly colorless due to the reduction of $\mathrm{Au}^{\mathrm{III}}$ to $\mathrm{Au}^{\mathrm{I}}$. For the following final reaction step, $10 \mu \mathrm{L}$ of the seed solution was added, and the mixture was gently mixed for $10 \mathrm{~s}$ and left undisturbed for at least $3 \mathrm{~h}$. After ca. $3 \mathrm{~min}$, the colorless solution changed to purple indicating the formation of gold nanorod particles (GNRs).

Gold nanocuboid preparation In a typical experiment, $5 \mathrm{~mL}$ of a $2.0 \times 10^{-2} \mathrm{~mol} \mathrm{~L}^{-1} \mathrm{CTAB}$ solution was mixed with $1.25 \mathrm{~mL}$ of $2.0 \times 10^{-3} \mathrm{~mol} \mathrm{~L}^{-1} \mathrm{HAuCl}_{4}$ at $25^{\circ} \mathrm{C}$, into which $12.5 \mu \mathrm{L}$ of $0.010 \mathrm{~mol} \mathrm{~L}^{-1} \mathrm{CuSO}_{4}$ was added. Then, $0.75 \mathrm{~mL}$ of a $0.10 \mathrm{~mol} \mathrm{~L}^{-1}$ freshly prepared AA solution was added. The solution turned from orange to colorless. This solution was used as growth solution. Thereafter, $1.25 \mu \mathrm{L}$ of the seed 
solution was added to the growth solution at $27^{\circ} \mathrm{C}$. The color of the solution gradually changed to violet-red within $2-$ 10 min indicating the formation of gold nanocuboid particles (GNCs).

Gold nanopolyhedron preparation A procedure similar to that above was used for the polyhedron preparation. Typically, $12.5 \mu \mathrm{L}$ of $1.0 \times 10^{-2} \mathrm{~mol} \mathrm{~L}^{-1}$ silver nitrate and $12.5 \mu \mathrm{L}$ of $1.0 \times 10^{-2} \mathrm{~mol} \mathrm{~L}^{-1} \mathrm{CuSO}_{4}$ were jointly added. Finally, $1.25 \mu \mathrm{L}$ of the seed solution was added to the growth solution at $25^{\circ} \mathrm{C}$. The color of the solution gradually changed to brownish purple. The combination of silver and copper ions promotes the polyhedron formation.

Cleaning procedure of AuNPs The synthesized AuNP solutions were centrifugated in order to remove a large amount of excess surfactant and also to separate the synthesized AuNPs from the other undesired shape particles. Therefore, at a controlled temperature of $27^{\circ} \mathrm{C}, 5 \mathrm{~mL}$ of gold solutions was centrifugated at 14,000 (GNSs), 12,000 (GNRs), and 10, $000 \mathrm{rpm}$ (GNCs and GNPs) for $12 \mathrm{~min}$. The supernatant was removed and the solid part was washed with ultrapure water three times.

UV-vis absorption spectroscopy measurements Absorption spectra of the GNRs solution were measured using Thermo Fisher Helios Omega UV-vis, near infrared spectrophotometer (NIR). Typical quartz cells of $1 \mathrm{~cm}$ optical path length were used for all spectra measurements. Each sample was prepared by dilution of $1 \mathrm{~mL}$ of GNRs initial solution with $3 \mathrm{~mL}$ of ultrapure water. The UV-visible absorption signal was recorded from 400 to $1,100 \mathrm{~nm}$.

Dynamic light scattering (DLS) measurements The effective hydrodynamic size and the zeta potential of synthesized AuNPs were estimated using a Zetasizer Nano-ZS, model ZEN 3600, from Malvern Instruments Ltd., based on multiple light scattering methods; it detects concentration variation in the colloid by scanning the whole height of the sample in transmission and backscattering. Typically, $1.2 \mathrm{~mL}$ of $5 \mu \mathrm{g} \mathrm{mL} \mathrm{L}^{-1}$ of clean AuNPs was introduced in the Zetasizer cell to evaluate the effective hydrodynamic size and the dispersion stability of the AuNPs solution which will be used as a catalytic ink. All sizes reported herein were based on intensity average. The intensity of the average particle size was obtained using a nonnegative least squares analysis method. For each sample, the measurement was performed with a fixed run time of $10 \mathrm{~s}$.

Transmission electron microscopy analysis The morphology and the size of the prepared gold nanoparticles were observed with a transmission electron microscope (TEM), a JEOL 2100 UHR $(200 \mathrm{kV})$ electron microscope equipped with $\mathrm{LaB}_{6}$ filament. TEM grids were prepared by placing one drop of the particle solution on a copper grid. This drop was dried in nitrogen atmosphere.

All the electrochemical experiments were carried out at a controlled temperature of $20^{\circ} \mathrm{C}$. The supporting electrolyte was a $0.1 \mathrm{~mol} \mathrm{~L}^{-1} \mathrm{NaOH}$ solution. A typical three-electrode Pyrex glass cell was employed. The reference electrode was a reversible hydrogen electrode (RHE). All potentials are referred to this reference electrode. The working electrode was a glassy carbon disk (GC) of $0.071 \mathrm{~cm}^{2}$ mounted in Teflon. The counter electrode was a glassy carbon slab electrically connected with a gold wire. Before any electrochemical measurement, the electrolyte was deaerated by bubbling nitrogen. The nitrogen flow is maintained during the experiment to avoid introducing any oxygen in the electrolyte. Before each experiment, the GC electrode was polished with alumina 0.5 and $0.1 \mu \mathrm{m}$, respectively, followed by several ultrasonic cleanings in ultrapure water. Afterwards, a cyclic voltammogram of the $\mathrm{GC}$ electrode is recorded in the supporting electrolyte to insure the cleanliness of the cell. After synthesis, the colloidal suspension was collected by centrifugation for subsequent physical and electrochemical characterizations. From this step, the excess of surfactant and the nondesired shape was removed. Gold nanoparticles were first cleaned by centrifugation before their deposition onto a glassy carbon disk, then the working electrode was introduced into the electrolyte under a controlled potential. Voltammetric experiments were performed with a potentiostat (EG\&G Princeton Applied Research Model 362) monitored by a computer. The electrochemical cleaning step of AuNPs electrodes was extensively described in the literature [28].

All the current densities in the present work were obtained by dividing the current by the real surface area of each catalytic layer. The real surface area (electrochemically active surface area, EASA) of AuNPs electrodes can be estimated by the charge corresponding to the reduction of the oxide monolayer on the gold surface. This charge also depends on the value of the upper potential limit and equal to $482 \mu \mathrm{C} \mathrm{cm}^{-2}$ in our case [36]. Therefore, the calculated EASA of GNRs, GNCs, GNPs, and GNSs are 0.075, 0.025, 0.054 and $0.012 \mathrm{~cm}^{2}$, respectively.

\section{Results and discussion}

UV-visible, zeta potential measurements and TEM characterizations

Figure 1 shows the shape-dependent UV-vis spectra of the different AuNPs solutions. For the GNRs, the surface plasmon resonance corresponding to the longitudinal component is observed at $793 \mathrm{~nm}[4,14,37]$. However, the other AuNPs present mostly the plasmon resonance excitation at 520,555, and $560 \mathrm{~nm}$ for GNSs, GNCs and GNPs, respectively. In 
Fig. 1 UV-visible absorption spectra of suspended AuNPs solutions: GNCs (dashed-dotted line), GNPs (dotted line), GNSs (dashed line), and GNRs (solid line). The inset image shows the colors of the AuNPs solutions

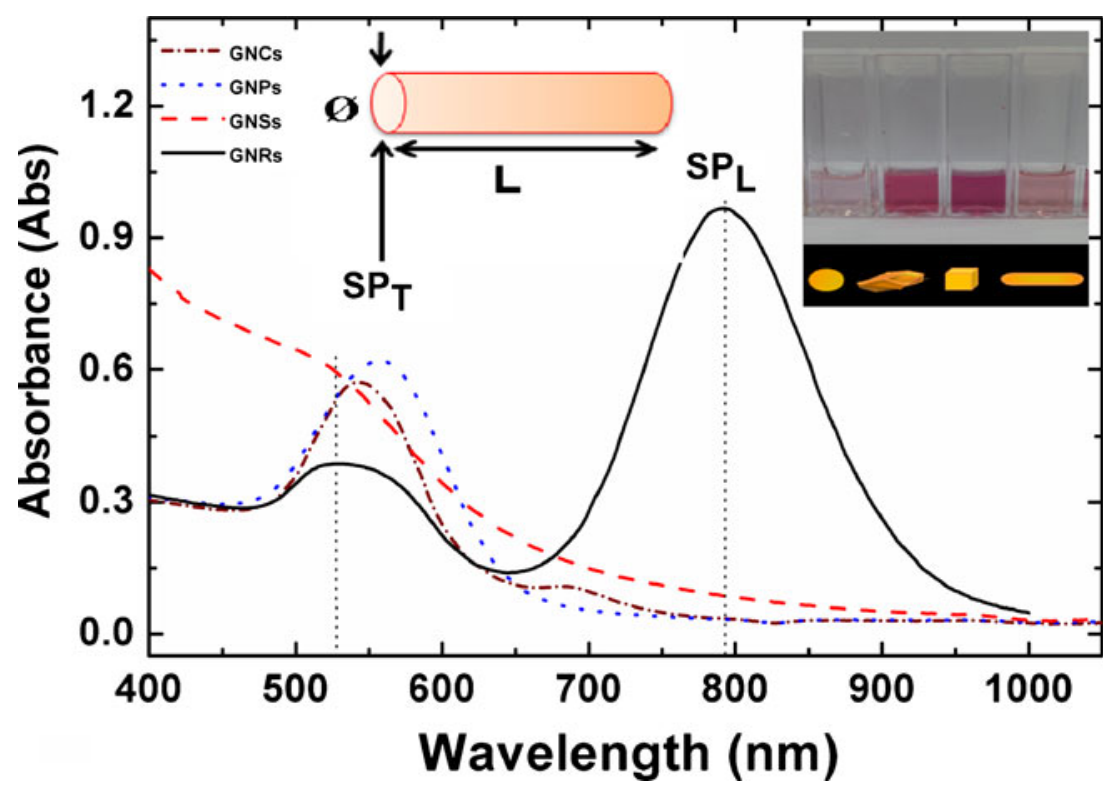

addition, the GNCs show another plasmon resonance excitation at $680 \mathrm{~nm}$ which can be assigned to the quadrupole plasmon resonance mode [38] or to the few anisotropic nanoparticles observed during the synthesis. The inset image in Fig. 1 illustrates the different colors of the gold nanoparticle solutions.

After the cleaning step by centrifugation, the AuNPs solutions obtained were optically, spatially homogeneous and can be used for electrochemical investigations. Preventing any nanoparticle aggregation in the colloidal solution after removal of the surfactant can be the way to maintain their properties for various applications. Besides, the size and the shape of the particles and the stability of colloid suspension depend on the environment, i.e. the solvent which contains the particles [39]. Therefore, the study of the free particles' environment becomes essential. The aggregation of the particles leads to a modification of their surface structure, then to an increase of their size. In this study, the measurement of the zeta potential of the samples was performed for understanding the stability of the free gold solution. According to the literature, nanoparticles with zeta potentials greater than $+30 \mathrm{mV}$ or less than $-30 \mathrm{mV}$ have sufficient electrostatic repulsion to remain stable in solution [40]. Nanoparticles are stabilized either by charge or steric strains. Table 1 shows the hydrodynamic size and the zeta potential values of AuNPs solutions. No sedimentation was observed. For AuNPs preparation, CTAB has been used as surfactant. The zeta potential of $0.1 \mathrm{~mol} \mathrm{~L}^{-1}$ CTAB leads to a positive value $c a$. $+59 \pm 12 \mathrm{mV}$. This positive value strongly imposes the positive charge to the nanoparticles synthesized by CTAB. A high value $(+75 \pm 11 \mathrm{mV})$ of zeta potential was obtained for spherical AuNPs because of their facility for the Brownian motion. High particle sizes lead to low zeta potential values as in the case of GNCs and GNPs.
The experimental hydrodynamic size obtained for GNRs is $37 \mathrm{~nm}$ while their length by TEM is $33.2 \pm 6.0 \mathrm{~nm}$.

Figure 2 shows the TEM images of synthesized AuNPs. The AuNPs are quite uniform in shape and size as expected (micrographs $(a)-(d)$ ). However, a few undesired shapes are observed in the GNRs and GNCs samples. Typically, the average particle sizes are $6.2 \pm 1.8,29.2 \pm 2.9$ and $36.8 \pm$ $4.9 \mathrm{~nm}$ for spherical, cuboid and polyhedral shapes, respectively. The GNRs have an aspect ratio of $3.3 \pm 0.7$ for an average length of $33.2 \pm 6.0 \mathrm{~nm}$. The percentage of the nonrod-shaped nanoparticles represents about $5 \%$ in this sample. For GNCs, the average particle size is $29 \pm 3 \mathrm{~nm}$ and this sample also contains around $14 \%$ of noncuboid particles. Typically, the average particle sizes are $6 \pm 2$ and $37 \pm 5 \mathrm{~nm}$ for spherical and polyhedral shapes, respectively (see Supplementary Material). In addition, the high-resolution transmission electron microscopy images of GNRs present some dislocation already examined by Wang et al. [41] which can affect their electrochemical behavior.

\section{Electrochemical characterization of the AuNPs surface}

Figure 3 shows the cyclic voltammetry of GNSs in $0.1 \mathrm{~mol} \mathrm{~L}^{-1}$ $\mathrm{NaOH}$ recorded at $20 \mathrm{mV} \mathrm{s}^{-1}$ and $20^{\circ} \mathrm{C}$. This $\mathrm{CV}$ represents the typical behavior of spherical gold nanoparticles in alkaline medium. Three important regions can be observed: during the positive scan, the double layer region observed from 0.05 to $0.9 \mathrm{~V}$ follows by the oxidation of the GNSs surface from 0.9 to $1.6 \mathrm{~V}$ leading to the oxides' formation and the reduction of these oxides during the negative sweep from 1.4 to $0.85 \mathrm{~V}$. In addition, the oxygen evolution begins on these NPs at $1.6 \mathrm{~V}$. In the double layer region which corresponds to the low currents, the chemisorption of $\mathrm{OH}^{-}$species takes place at around $0.8 \mathrm{~V}$. 
Table 1 Summary of physical properties of AuNPs (UV-vis, TEM, DLS data)

\begin{tabular}{|c|c|c|c|c|c|}
\hline \multirow[t]{2}{*}{ AuNP solution } & \multicolumn{2}{|c|}{$\begin{array}{l}\text { Plasmon absorption } \\
\text { wavelength (nm) }\end{array}$} & \multirow{2}{*}{$\begin{array}{l}\begin{array}{l}\text { Mean particle } \\
\text { size }(\mathrm{nm})\end{array} \\
\text { Aspect ratio }\end{array}$} & \multirow[t]{2}{*}{$\begin{array}{l}\text { Effective hydrodynamic } \\
\text { size } D_{\mathrm{H}}(\mathrm{nm})\end{array}$} & \multirow[t]{2}{*}{$\begin{array}{l}\text { Zeta potential } \\
(\mathrm{mV})\end{array}$} \\
\hline & $\mathrm{SP}_{\mathrm{T}}$ & $\mathrm{SP}_{\mathrm{L}}$ & & & \\
\hline \multirow[t]{2}{*}{ Rod } & 535 & 793 & $3.3 \pm 0.7$ & 37 & $45 \pm 19$ \\
\hline & SPR & & & & \\
\hline Spherical & 520 & & $6.2 \pm 1.8$ & 37 & $75 \pm 11$ \\
\hline Cuboid & 555 & & $29.2 \pm 2.9$ & 54 & $26 \pm 10$ \\
\hline Polyhedron & 560 & & $36.8 \pm 4.9$ & 59 & $28 \pm 5$ \\
\hline CTAB & - & - & - & & $59 \pm 12$ \\
\hline
\end{tabular}

This adsorption is essential for the surface oxidation of AuNPs. The CV comparison of the different AuNPs synthesized was made and presented in the Supplementary Material.

The surface structure of noble metal nanoparticles can be characterized by electrochemical methods [18, 28]. Indeed, the UPD of lead on gold material is one of the sensitive electrochemical methods, which reveals the crystallographic structure and quantifies the ratio of the existing facets $[18,28]$. Figure 4 shows the CVs of the different AuNPs electrodes, GNRs (solid line), GNPs (dashed line), GNCs (dashed dot line), and GNSs (dot line) in $0.1 \mathrm{~mol} \mathrm{~L}^{-1} \mathrm{NaOH}+1 \mathrm{mmol} \mathrm{L}-1 \mathrm{~Pb}\left(\mathrm{NO}_{3}\right)_{2}$. During the negative potential sweep from 0.85 to $0.25 \mathrm{~V}$ on the AuNPs electrode, two peaks assigned to deposition of lead on (110) and (111) facets were observed at around 0.52 and $0.38 \mathrm{~V}$. The three electrodes (GNSs, GNPs and GNRs) do not show a significant peak corresponding to the (100) facet.

Fig. 2 Transmission electron micrographs (TEM) and highresolution transmission electron micrographs (HRTEM) showing the lattice planes and the exposed facets of GNSs, GNRs, GNCs, and GNPs

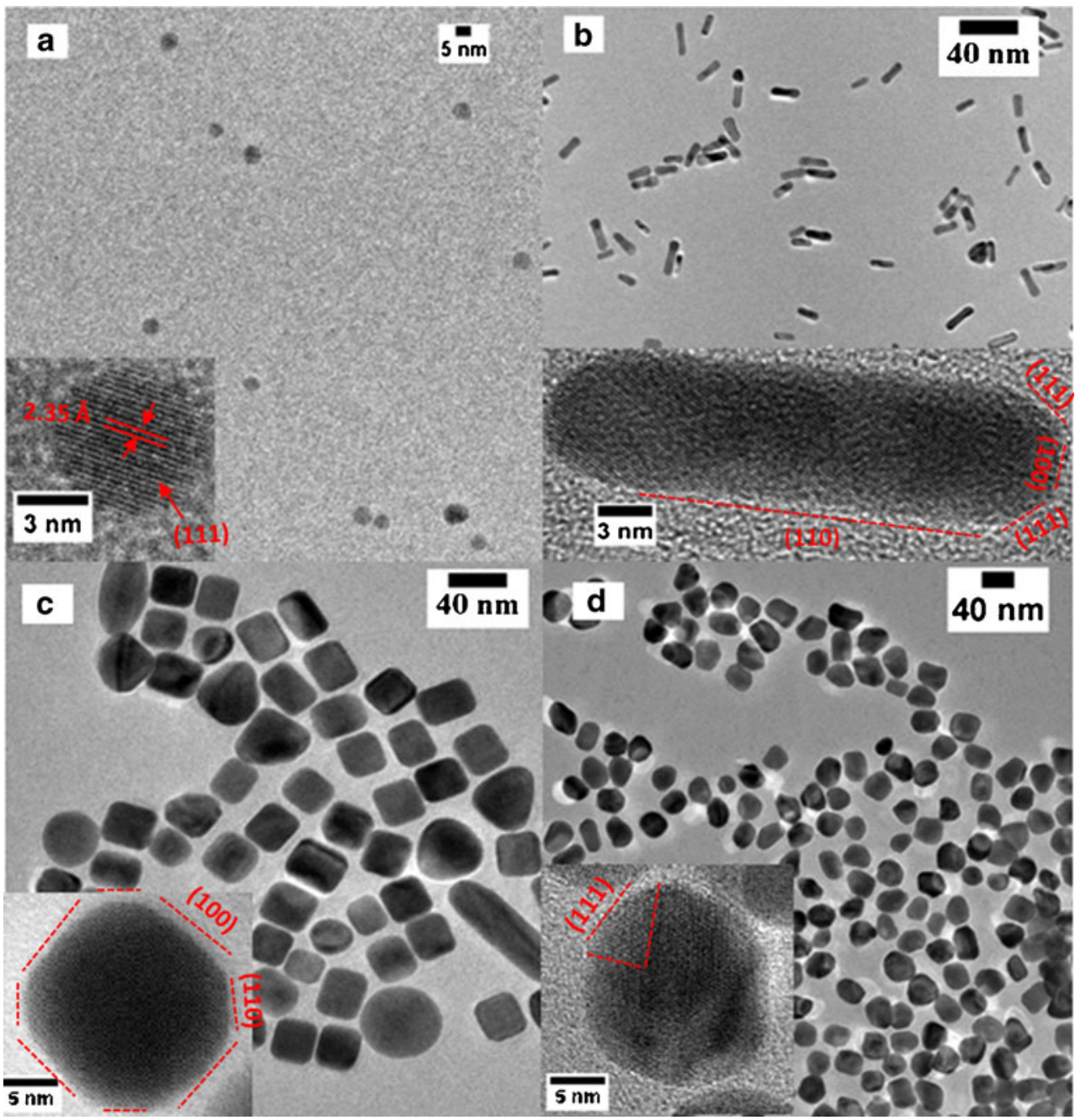


Fig. 3 Cyclic voltammogram of GNSs electrode in $0.1 \mathrm{~mol} \mathrm{~L}^{-1}$ $\mathrm{NaOH}$ recorded at $20 \mathrm{mV} \mathrm{s}^{-1}$ and at controlled temperature of $20^{\circ} \mathrm{C}$

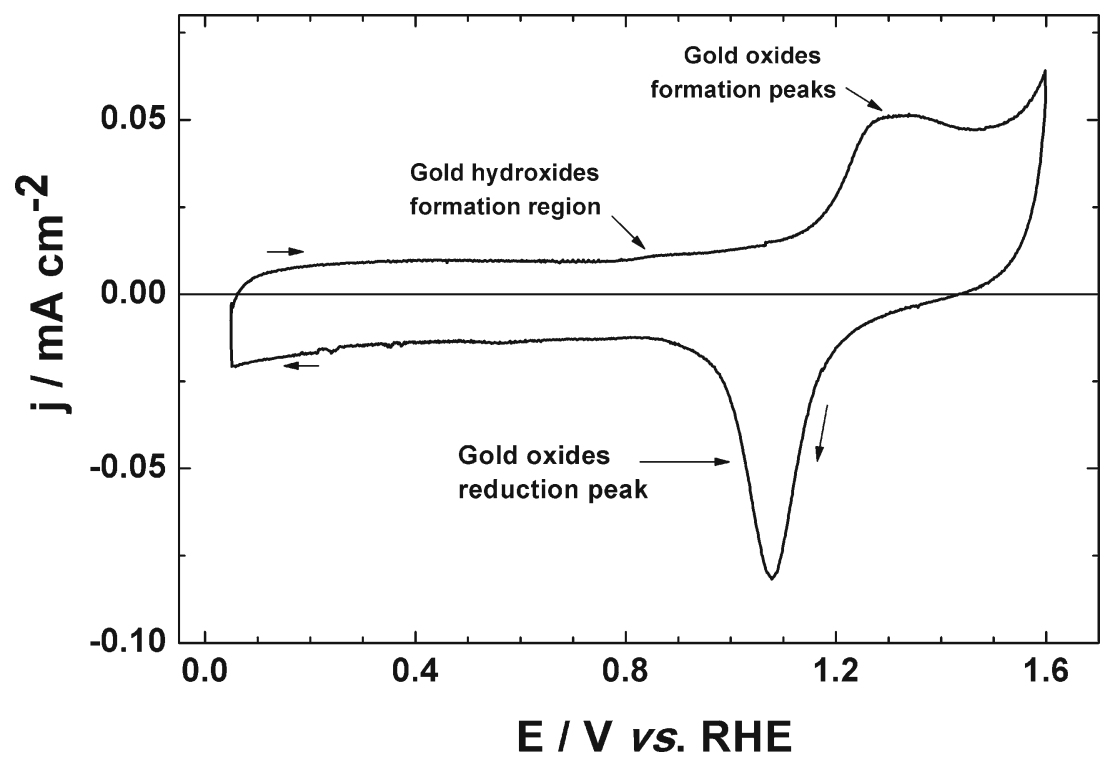

However, this is clearly observed for the GNCs electrode at $0.43 \mathrm{~V}$. During the positive potential sweep, three stripping peaks corresponding to the desorption of lead layer on (111), (100) and (110) facets were observed at around $0.41,0.47$ and $0.57 \mathrm{~V}$, respectively. The desorption peak on the (100) facet is well defined and high in activity for the GNCs compared to GNRs, as expected. No desorption peak of lead on (100) was observed for GNSs and GNPs. The lead desorption on (111) and (110) facets on GNCs is due to their truncated edges. According to Murphy et al. [14], GNRs can exhibit (100) or (111) facets at the end of the rods. In addition, an increase of (111) facets along the GNRs' side can be observed because of the crystallization defects [41].
Glucose oxidation on gold nanoparticles

On the low-index single-crystal gold electrodes, it was mentioned that the oxidation of the glucose depends on such surface structure and on the adsorbed intermediates [26, 33]. The formation of $(\mathrm{OH})_{\text {ads }}$ on $\mathrm{Au}$ is crucial for the electrochemical oxidation of glucose [30]. This oxidation is assumed to occur through the interaction between the adsorbed hemiacetal group and $(\mathrm{OH})_{\text {ads }}$. It is generally accepted that the $\mathrm{AuOH}$ sites on the Au surface act as the active species for glucose oxidation [42]. Thereby, the oxidation of glucose strongly depends on the number of $\mathrm{AuOH}$ sites. The first step of the oxidation of glucose in alkaline media involves the adsorption of glucose on the Au surface through the anomeric carbon leading to the dehydrogenation process via the formation of an
Fig. 4 Voltammetric UPD profiles of the different AuNPs (GNSs, GNRs, GNCs and GNPs) in $0.1 \mathrm{~mol} \mathrm{~L}^{-1} \mathrm{NaOH}+$

$1 \mathrm{mmol} \mathrm{L}^{-1} \mathrm{~Pb}\left(\mathrm{NO}_{3}\right)_{2}$ recorded at $20 \mathrm{mV} \mathrm{s}^{-1}$ and at controlled temperature of $20^{\circ} \mathrm{C}$

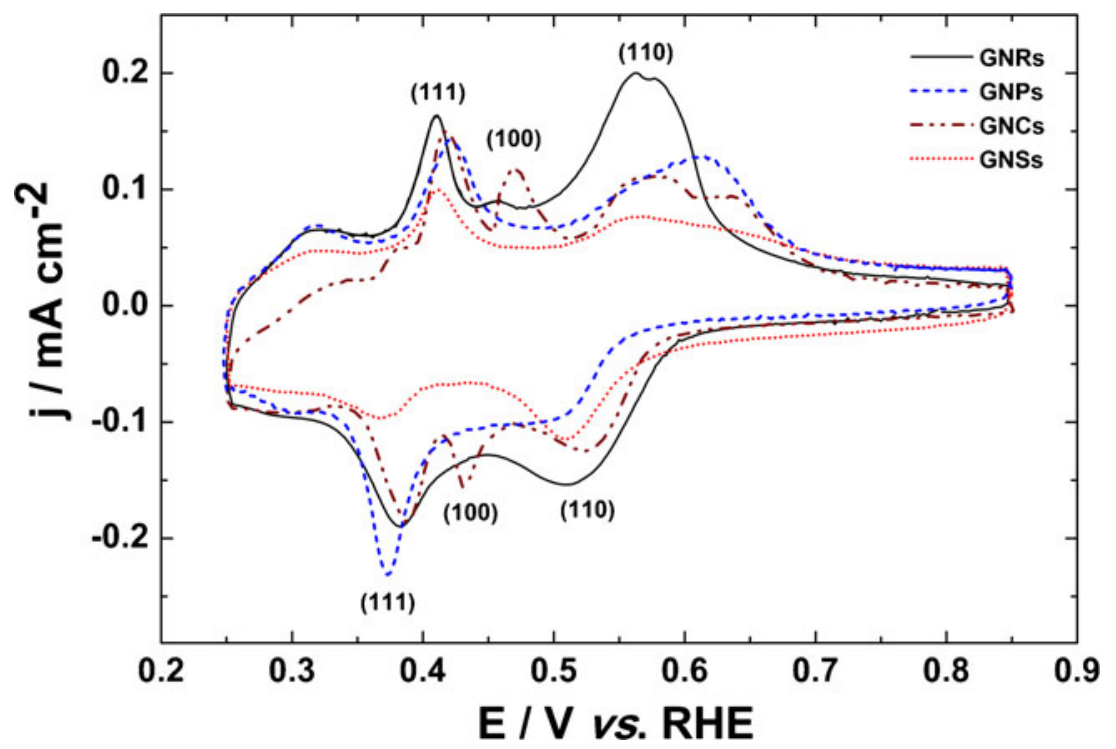


Fig. 5 Voltammograms of the different AuNP (GNSs, GNRs, GNCs and GNPs) electrodes in $0.1 \mathrm{~mol} \mathrm{~L}^{-1} \mathrm{NaOH}+10 \mathrm{mmol} \mathrm{L}^{-1}$ glucose, recorded at $20 \mathrm{mV} \mathrm{s}^{-1}$ and at controlled temperature of $20{ }^{\circ} \mathrm{C}$

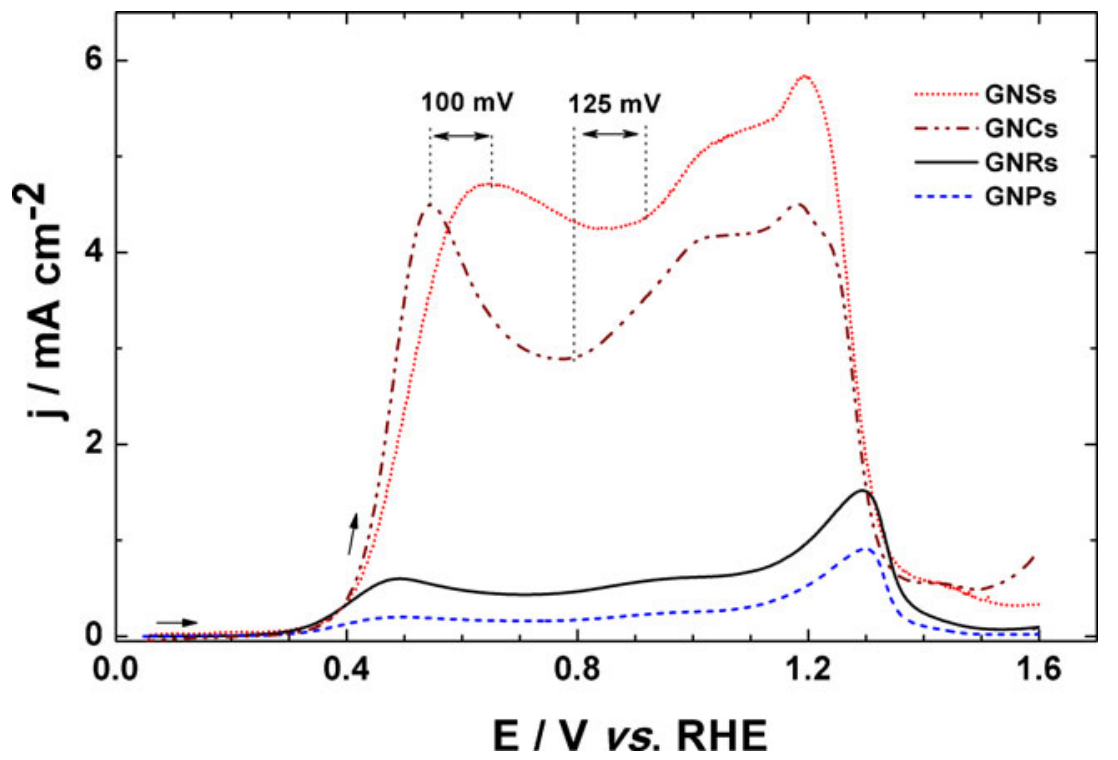

adsorbed radical. This process leads to the formation of gluconolactone [29, 33]. Furthermore, gluconolactone can be hydrolyzed in solution to give sodium gluconate [30, 42]. The second step deals with the oxidation of adsorbed intermediates or gluconolactone with the adsorbed $\mathrm{OH}$ species. Several products can be obtained as indicated in the literature [29]. Figure 5 presents the positive potential scan of the glucose oxidation reaction on the different AuNPs. The oxidation of glucose begins at ca. $0.3 \mathrm{~V}$ for all materials followed by the first oxidation peak which is associated with the formation of gluconolactone species. GNCs (dashed dot line) and GNSs (dot line) present high activities for this process. For GNCs, this oxidation peak is sharp and its maximum appears at $0.54 \mathrm{~V}(100 \mathrm{mV}$ lower than for GNSs). The lowest activity of the dehydrogenation was observed with GNPs. After this process, the oxidation continues in a large range of potential from 0.8 to $1.3 \mathrm{~V}$. GNRs (solid line) and GNPs (dashed line) show an overlap shoulder followed by a maximum oxidation peak at $1.3 \mathrm{~V}$. However, this peak is observed at $1.2 \mathrm{~V}$ for GNSs and GNCs. The high current density observed for GNSs can be related to their small size (around $6 \pm 2 \mathrm{~nm}$ ) and their electronic surface structure. The catalytic effect on GNCs depends on their structure, i.e. the number of sites of low coordination. These NPs show a well-defined structure. GNCs exhibit the mean (100) and (110) facets that promote the dehydrogenation of the molecule of glucose at low potential $(0.54 \mathrm{~V})$ compared to the other nanostructured materials. These facets are the most favorable for this reaction $[33,43]$.

\section{Conclusion}

Different shape-controlled gold nanoparticles were synthesized by wet chemical methods. The UV-vis spectroscopy measurements and transmission electron microscopy characterizations showed a fine distribution in size and shape of the AuNPs. The zeta potential measurements permitted the confirmation of spherical nanoparticles as more stable than the anisotropic ones.

The electrochemical characterization by UPD showed that the GNRs and GNCs present the three low-index facets, while the GNSs and GNPs do not display the (100) facet. These different surface structures affect strongly the electrocatalytic activity of the gold nanoparticles. The dehydrogenation reaction occurs at low potential on GNCs, whereas the GNSs show the highest current density for this reaction. This study shows clearly that the shape and the structure of the nanoparticles should be combined to understand their electrocatalytic activity.

Acknowledgments The authors acknowledge the CNRS and the Region Poitou-Charentes for their financial support.

Open Access This article is distributed under the terms of the Creative Commons Attribution License which permits any use, distribution, and reproduction in any medium, provided the original author(s) and the source are credited.

\section{References}

1. Huang X, El-Sayed MA (2010) Gold nanoparticles: Optical properties and implementations in cancer diagnosis and photothermal therapy. J Adv Res 1(1):13-28

2. Daniel MC, Astruc D (2004) Gold nanoparticles: assembly, supramolecular chemistry, quantum-size-related properties, and applications toward biology, catalysis, and nanotechnology. Chem Rev 104: 293-346

3. Cui C, Gan L, Li HH, Yu SH, Heggen M, Strasser P (2012) Octahedral PtNi Nanoparticle Catalysts: Exceptional Oxygen 
Reduction Activity by Tuning the Alloy Particle Surface Composition. Nano Lett 12(11):5885-5889

4. Yu, Chang SS, Lee CL, Wang CRC (1997) Gold nanorods:i electrochemical synthesis and optical properties. J Phys Chem B 101(34): 6661-6664

5. Sau TK, Murphy CJ (2004) Room temperature, high-yield synthesis of multiple shapes of gold nanoparticles in aqueous solution. J Am Chem Soc 126(28):8648-8649

6. Sun Y, Xia Y (2002) Shape-controlled synthesis of gold and silver nanoparticles. Science 298(5601):2176-2179

7. Shankar SS, Rai A, Ankamwar B, Singh A, Ahmad A, Sastry M (2004) Biological synthesis of triangular gold nanoprisms. Nat Mater 3(7):482-488

8. Huang CJ, Chiu PH, Wang YH, Yang CF (2006) Synthesis of the gold nanodumbbells by electrochemical method. J Colloid Interface Sci 303(2):430-436

9. Langille MR, Personick ML, Zhang J, Mirkin CA (2012) defining rules for the shape evolution of gold nanoparticles. J Am Chem Soc 134(35):14542-14554

10. Straney PJ, Andolina CM, Millstone JE (2013) Seedless initiation as an efficient, sustainable route to anisotropic gold nanoparticles. Langmuir 29(13):4396-4403

11. Yong KT, Sahoo Y, Swihart M, Schneeberger P, Prasad P (2008) Templated Synthesis of Gold Nanorods (NRs): The Effects of Cosurfactants and Electrolytes on the Shape and Optical Properties. Top Catal 47(1-2):49-60

12. Zhu YJ, Hu XL (2003) Microwave-polyol preparation of singlecrystalline gold nanorods and nanowires. Chem Lett 32(12):1140-1141, 2

13. Simakin AV, Voronov VV, Shafeev GA, Brayner R, Bozon-Verduraz F (2001) Nanodisks of $\mathrm{Au}$ and $\mathrm{Ag}$ produced by laser ablation in liquid environment. Chem Phys Lett 348(3-4):182-186

14. Sau TK, Murphy CJ (2004) Seeded high yield synthesis of short Au nanorods in aqueous solution. Langmuir 20(15):6414-6420

15. Perez-Juste J, Pastoriza-Santos I, Liz-Marzan LM, Mulvaney P (2005) Gold nanorods: synthesis, characterization and applications. Coord Chem Rev 249(17-18):1870-1901

16. Sun J, Guan M, Shang T, Gao C, Xu Z, Zhu J (2008) Selective synthesis of gold cuboid and decahedral nanoparticles regulated and controlled by Cu2 + Ions. Cryst Growth Des 8(3):906-910

17. Hernandez J, Solla-Gullon J, Herrero E, Aldaz A, Feliu JM (2005) Characterization of the surface structure of gold nanoparticles and nanorods using structure sensitive reactions. J Phys Chem B 109(26): 12651-12654

18. Hernandez J, Solla-Gullon J, Herrero E, Feliu JM, Aldaz A (2009) In Situ surface characterization and oxygen reduction reaction on shapecontrolled gold nanoparticles. J Nanosci Nanotechnol 9(4):2256-2273

19. Hvolbæk B, Janssens TVW, Clausen BS, Falsig H, Christensen CH, Nørskov JK (2007) Catalytic activity of Au nanoparticles. Nano Today 2(4):14-18

20. Guo Z, Fan X, Liu L, Bian Z, Gu C, Zhang Y, Gu N, Yang D, Zhang J (2010) Achieving high-purity colloidal gold nanoprisms and their application as biosensing platforms. J Colloid Interface Sci 348(1): 29-36

21. Tominaga M, Shimazoe T, Nagashima M, Kusuda H, Kubo A, Kuwahara Y, Taniguchi I (2006) Electrocatalytic oxidation of glucose at gold-silver alloy, silver and gold nanoparticles in an alkaline solution. J Electroanal Chem 590(1):37-46

22. Tominaga M, Shimazoe T, Nagashima M, Taniguchi I (2005) Electrocatalytic oxidation of glucose at gold nanoparticle-modified carbon electrodes in alkaline and neutral solutions. Electrochem Commun 7(2):189-193

23. Cho S, Shin H, Kang C (2006) Catalytic glucose oxidation on a polycrystalline gold electrode with an amalgamation treatment (TM 05092). Electrochim Acta 51(18):3781-3786

24. Jin CC, Taniguchi I (2007) Electrocatalytic oxidation of glucose on gold nanocomposite electrodes. Chem Eng Technol 30(9):1298-1301
25. Nelson T (2009) Recent progress in electrochemical oxidation of saccharides at gold and copper electrodes in alkaline solutions. Bioelectrochemistry 76(1-2):195-200

26. Wang J, Gong J, Xiong Y, Yang J, Gao Y, Liu Y, Lu X, Tang Z (2011) Shape-dependent electrocatalytic activity of monodispersed gold nanocrystals toward glucose oxidation. Chem Commun 47(24): 6894-6896

27. Tonda-Mikiela P, Napporn TW, Morais C, Servat K, Chen A, Kokoh KB (2012) Synthesis of gold-platinum nanomaterials using bromide anion exchange-synergistic electroactivity toward $\mathrm{CO}$ and glucose oxidation. J Electrochem Soc 159(11):H828-H833

28. Hebié S, Cornu L, Napporn TW, Rousseau J, Kokoh BK (2013) Insight on the surface structure effect of free gold nanorods on glucose electrooxidation. J Phys Chem C 117(19):9872-9880, 3

29. Kokoh KB, Léger JM, Beden B, Lamy C (1992) "On line" chromatographic analysis of the products resulting from the electrocatalytic oxidation of d-glucose on Pt. Au and adatoms modified Pt electrodes-Part I. Acid and neutral media. Electrochim Acta 37(8): 1333-1342

30. Hsiao MW, Adžić RR, Yeager EB (1996) Electrochemical oxidation of glucose on single crystal and polycrystalline gold surfaces in phosphate buffer. J Electrochem Soc 143(3):759-767

31. Chen Y, Schuhmann W, Hassel AW (2009) Electrocatalysis on gold nanostructures: is the 110 facet more active than the 111 facet? Electrochem Commun 11(10):2036-2039

32. Vuyyuru KR, Strasser P (2012) Oxidation of biomass derived 5hydroxymethylfurfural using heterogeneous and electrochemical catalysis. Catal Today 195(1):144-154

33. Adzic RR, Hsiao MW, Yeager EB (1989) Electrochemical oxidation of glucose on single crystal gold surfaces. J Electroanal Chem Interfacial Electrochem 260(2):475-485

34. Martins A, Ferreira V, Queirós A, Aroso I, Silva F, Feliu J (2003) Enantiomeric electrooxidation of d- and l-glucose on chiral gold single crystal surfaces. Electrochem Commun 5(9):741-746

35. Habrioux A, Hebié S, Napporn T, Rousseau J, Servat K, Kokoh KB (2011) One-Step synthesis of clean and size-controlled gold electrocatalysts: modeling by taguchi design of experiments. Electrocatalysis 2(4):279-284

36. Finot MO, Braybrook GD, McDermott MT (1999) Characterization of electrochemically deposited gold nanocrystals on glassy carbon electrodes. J Electroanal Chem 466(2):234-241

37. Eustis S, El-Sayed MA (2006) Determination of the aspect ratio statistical distribution of gold nanorods in solution from a theoretical fit of the observed inhomogeneously broadened longitudinal plasmon resonance absorption spectrum. J Appl Phys 100(4):044324

38. Lee J-H, Kamada K, Enomoto N, Hojo J (2007) Morphology-selective synthesis of polyhedral gold nanoparticles: What factors control the size and morphology of gold nanoparticles in a wet-chemical process. J Colloid Interface Sci 316(2):887-892

39. Pavlin M, Bregar VB (2012) Stability of nanoparticle suspensions in different biologically revelant media. Dig J Nanomater Biostructure 7(4):1389-1400

40. Gauggel S, Derreza-Greeven C, Wimmer J, Wingfield M, Bvd B, Dietrich DR (2012) Characterization of biologically available wood combustion particles in cell culture medium. Altex 29(2):183-200

41. Wang ZL, Gao RP, Nikoobakht B, El-Sayed MA (2000) Surface reconstruction of the unstable 110 Surface in Gold Nanorods. J Phys Chem B 104(23):5417-5420

42. Aoun SB, Dursun Z, Koga T, Bang GS, Sotomura T, Taniguchi I (2004) Effect of metal ad-layers on $\mathrm{Au}(111)$ electrodes on electrocatalytic oxidation of glucose in an alkaline solution. J Electroanal Chem 567(2):175-183

43. Beden B, Çetin I, Kahyaoglu A, Takky D, Lamy C (1987) Electrocatalytic oxidation of saturated oxygenated compounds on gold electrodes. J Catal 104(1):37-46 